\title{
Repairing Conversation and Foreign Language Proficiency
}

\author{
Ebrahim Khodadady \\ Ferdowsi University of Mashhad, Iran \\ Email: ekhodadady@ ferdowsi.um.ac.ir \\ Jassem Alifathabadi \\ Ferdowsi University of Mashhad, Iran
}

\begin{abstract}
This study explored whether there was a relationship between the level of language proficiency and repairing conversation in English classes. For this purpose, sixty participants learning English as foreign language were divided into four coed classes, i.e., two intermediate and two advanced classes, and two sessions of each class were recorded during an academic term offered in a private language school in Mashhad, Iran. The cases of repair in the conversations of these learners were identified and transcribed separately for both groups during the term. They were then categorized based on the place of repair initiation and the type of repair completion. The frequencies of cases were then subjected to statistical tests conducted via the S-PLUS program. The results showed that both intermediate and advanced learners prefer self-repair over other repair. It was also found that they differ significantly from each other not only in the number of times they allow self-and-other repairs to occur but also in the frequency with which repair-initiations and repaircompletions are combined. The findings are discussed within a foreign language context.
\end{abstract}

Index Terms - repair initiation, repair-completion, self-repair, other-repair, S-PLUS, preference

\section{INTRODUCTION}

Conversation is one form of spoken interaction upon which language use is based. It is one of the most prevalent uses of human language through which people interact with each other, so all human societies depend on conversation to function in the most efficient way. According to Goodwin and Heritage (1990), "social interaction is the primordial means through which the business of the social world is transacted, the identities of its participants are affirmed or denied, and its cultures are transmitted, renewed and modified" (p.283).

Conversation has been of great importance to writers over a long period of time, but most of them have treated it on the basis of some prescriptive rules which should be taken into account during every social interaction. These rules show what is appropriate and what is not in different situations; however, what constitutes good or appropriate conversation rules varies from culture to culture and changes over time (Burke, 1993).

\section{A. Conversation Analysis}

The term conversation analysis (CA) has been used to describe a field that is informed by a broad range of disciplinary perspectives, including pragmatics, speech act theory, interactional sociolinguistics, ethnomethodology, and the ethnography of communication, variation analysis, communication theory, and social psychology (Schiffrin, 1991). In this study, those practices that have been carried out within an ethnomethodological tradition were followed in general and Stubbs (1983) in particular. The CA, according to Stubbs, is almost always used as a synonym for an ethnomethodological orientation to what Markee (2000) calls analysis of conversational data (ACD) which includes CA and other disciplinary perspectives.

The ideas explored in the CA were mainly influenced by two theories; the first was put forward by Goffman (1959) who emphasized the importance of face-to-face interaction. According to McKay and Hornberger (1996), "Goffman viewed interaction in terms of strategy and ritual and emphasized the importance of situation- the encounter as an attentionally focused gathering in which some aspects of the presentation of self are salient and others are downplayed or concealed" (p.285). The second and more powerful influence was from the works of Garfinkel (1967) and ethnomethodology. According to Ten Have (2004):

Ethnomethodology is a special kind of social inquiry, dedicated to explicating the ways in which members collectively create and maintain a sense of order and intelligibility in their social life. It has emerged as a distinctive perspective and style of social research in the teachings and publications of Harold Garfinkel (p.14).

Some conversation analysts (see Bilmes, 1992, 1993; Cicourel, 1992; Mehan, 1993; Moerman, 1988; Wilson, 1991) include ethnographic information into their analyses claiming that such information is necessary for a complete understanding of talk-in-interaction. In contrast, another group of researchers (e.g., Schegloff, 1987, 1990, 1991; 1992a) 
ignore ethnographic information of members' cultures or biographies to make an argument unless there is internal evidence in the conversational data to provide a warrant for the inclusion of such data.

The CA started with focus on casual, mundane conversation between friends and acquaintances, but now all forms of spoken interaction, including those in institutional contexts such as classrooms, doctor's surgeries, and courtrooms are also targets of analysts' attention (Drew \& Heritage, 1992). In all contexts, whether institutional or not, participants take turns usually one at a time, order and organize their talk sequentially and repair the problems they face in interaction in order to achieve their goals. The main concern of CA is these interactional arrangements and what participants do to accomplish their goals. Therefore, the main focus of CA analysts is on the organization of talk in interaction including: turn-taking, sequence organization and repair (Ellis \& Barkhuizen, 2005).

\section{B. Repair}

According to Liddicoat (2007), repair, which is relevant to all levels of talk, is itself a mechanism of conversation. It refers to the processes available to speakers through which they can deal with the problems which arise in their talk. Repair is a broader concept than simply the correction of errors in talk by replacing an incorrect form with a correct one, although such corrections are a part of repair. In fact many cases of repair seem to involve situations in which there is no error made by the speaker at all (Jefferson, 1987).

According to Schegloff, Jefferson and Sacks (1977), the organization of repair can be analyzed based on three different terms:

(1) The position of repair in relation to an initial trouble source

(2) The person who initiates repair (self or other) and who completes it (again self or other)

(3) Whether a repair is successful or unsuccessful.

As Liddicoat (2007) noted, "repair can be initiated by the speaker of the repairable (self-initiated repair) or it may be initiated by its recipient (other-initiated repair). In addition, a repair can be made by the speaker of the repairable item (self-repair) or it may be made by the recipient of the item (other-repair)" (p. 173). The combination of repair initiation and repair completion allows for possibility of four types of repair:

1. Self-initiated self-repair: the speaker of the repairable item both indicates a problem in the talk and resolves the problem.

2. Self-initiated other-repair: the speaker of the repairable item indicates a problem in the talk, but the recipient resolves the problem.

3. Other-initiated self-repair: the recipient of the repairable item indicates a problem in the talk and the speaker resolves the problem.

4. Other-initiated other-repair: the recipient of the repairable item both indicates a problem in the talk and resolves the problem.

Liddicoat (2007) also believed that repair is designed to resolve the trouble as quickly as possible and locations for repair are locations relative to the trouble source, so it is possible to identify five positions for repair, i.e., Same turn repair (in the same turn as the trouble source), Transition space repair (in the transition space following the turn containing the trouble source), Second position repair, Third position repair and Fourth position repair.

\section{Preference for Self-repair}

The positions mentioned for repair interact with repair initiation in such a way that each position provides an opportunity for a particular participant to initiate the repair. This means that self-initiation and other-initiation are also organized in terms of their positions sequentially. As shown in Figure 1, these two types of initiation are ordered so that possibilities for self-initiation come before possibilities for other initiation (Schegloff et al., 1977). According to Liddicoat (2007), the ordering provides a set of alternating possibilities in a way that each of these possible positions is available for repairing the same types of trouble source. They can be seen as a set of ordered possibilities for initiating repair in which the speaker (i.e. producer of the trouble) has the first opportunity to initiate a repair, either within the current turn or just after the current turn in the transition space (p.175).

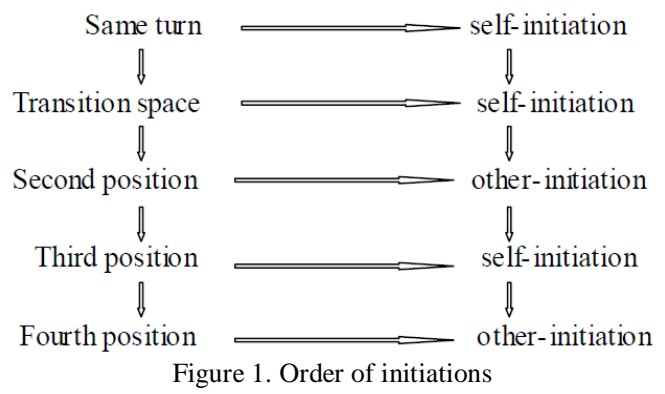

Schegloff (1992b) believed that if there was a problem with the original turn, it may be indicated in the second position, so responses to turns at talk are opportunities to display understanding or misunderstandings of prior talk. This means that talk in a turn in the second position may indicate a trouble source in the earlier turn i.e. same turn. When this 
happens, the speaker of the original trouble source may initiate repair in the next turn i.e. in third position in relation to the original turn. Talk in the second position may indicate a misunderstanding, but this misunderstanding may not become apparent until the third position. In this case, the recipient of the original turn may initiate repair in the next turn i.e. in fourth position relative to the original trouble (Liddicoat, 2007).

According to Schegloff et al. (1977), the fact that other-initiation normally occurs in the next turn after the trouble source is not an accidental artifact of turn-taking. It is, for example, possible for repair to occur during the turn in which the trouble source occurs when a recipient interrupts the current speaker. Other-initiated repair, however, does not normally occur during such a turn. This means that the typical first possible position for other-initiation is not simply the next turn, but it is also not sooner than the next. Furthermore, Schegloff et al. (1977) also argued that other-initiation may often be delayed in its own turn to allow an expanded transition space in which self-initiation could potentially occur. To sum up, it is not simply true that other-initiation is found after self-initiation; rather the repair system is organized to achieve such an ordering.

Schegloff et al. (1977) have also identified a preference for self-repair in conversation. They argue that this preference is not simply a matter of more number of instances of self-repair. Rather it is based on a system which is designed to achieve self-repair. The most salient feature of the system that favors self-repair is that the positions in which self-repair can happen precede the positions in which other repair take place, providing a structurally first opportunity for speakers to repair their own trouble sources. The first two possible repair positions (within the turn and within the transition space) are the possibilities for the speaker to initiate repair. To sum up, three of the five possible locations for repair are provided for the speaker who produced the trouble source and that these three positions represent three of the four possible spaces. The predominance of first locations for possible self-repair is further supported by the more number of success of repairs themselves. This means that many repairs are resolved before the possibility of other repair even arises. Besides, further possibilities for self-repair are created by the division of repair work into initiation and repair. Other-initiated repair most commonly leads to self-repair rather than other-repair. Particularly, second position other-initiated repair is usually designed to provide for self-repair.

According to Liddicoat(2007), most other-initiated repair techniques indicate that there was a trouble in the prior talk, but do not perform any operations on that talk. In some cases other-initiated repair does no more than indicating of a trouble while in other cases the repair initiator more explicitly identifies the trouble source. These second position turns are typically occupied only with initiating repair and pass the work of the repair itself to the next positioned turn, i.e., the first speaker who produced the trouble source. Based on this argument, the four repair types discussed above - selfinitiated self-repair, self-initiated other-repair, other-initiated self-repair and other-initiated other-repair- are not interactionally equal options because there is a strong preference for some of these types over the others.

Preferring certain types of repair does not, however, affect who initiates repair and the need to deal with trouble in talk applies equally to all participants if conversation is to work as a self-regulating system, so self-initiation and otherinitiation are alternatives responding to different interactional needs. Self-repair and other-repair are not though alternatives in the same way and the preference organization involved in repair is such that self-repair is favored over other-repair. Therefore, other-repair is not preferred and usually shows interactional modifications which affect the turn shape in which other-repair is found. Other-repairs are often done in a mitigated way, e.g., they may contain makers of uncertainty or they may be produced in question form. Markee (2000) also believed that there is a preference for self over other-correction in first language conversations and there is a strong possibility of it in second language talk. The present study attempts to explore the preference within a context in which English is learned as a foreign language (EFL).

\section{Methods}

\section{A. Participants}

Sixty, 30 male and 30 female, Iranian learners of English participated voluntarily in the study. Their age ranged between 16 and 27. The participants were divided into four coed classes, i.e., two intermediate and two advanced classes, so that their conversation repairing could not recorded as exactly as possible. They attended English classes twice a week for 20 sessions in a private language institute in Mashhad, Iran. Persian was the first language of all the participants and they learned English as a foreign language because they neither spoke nor heard it in their everyday conversations in the society.

\section{B. Procedure}

Before the term started, the researchers decided to record two sessions of both intermediate and advanced classes in which English was taught as a foreign language. The fourth and seventeenth sessions of these classes were chosen to get a representative sample of the participants' interactions with their teachers during the term. These sessions were recorded entirely from the beginning to the end. The recorded materials were then listened several times and the cases of repair were chosen separately for intermediate and advanced groups. The symbols and signs designed by Jefferson and published by Lerner (2004) were utilized to transcribe the cases of repair. They were then categorized two times, i.e., once based on the place of repair initiation and the other time based on the type of repair completion. 


\section{Data Analysis}

The cases of repair made in various positions by intermediate and advanced learners were counted and subjected to Chi-Square Test as well as Binomial Nonparametric Test. All data analyses were conducted in S-PLUS whose power lies in its convenient and useful way of organizing data, its wide variety of classical and modern modeling techniques, and its way of specifying models (MathSoft, 1999). The statistical tests were employed to test the following research hypotheses.

H1 There is a significant preference for self over other-repair among intermediate EFL learners.

$\mathrm{H} 2$ There is a significant preference for self over other-repair among advanced EFL learners.

H3. Intermediate and advanced EFL learners will not differ significantly from each other in their preference for self over other-repair.

\section{RESULTS}

Table 1 presents the descriptive statistics and binomial test of self-repairs (SRs) as well as other-repairs (ORs) made by intermediate EFL learners. As can be seen, the frequency of SRs, i.e., 99, is higher than ORs, i.e., 50. The ChiSquare Test showed that the difference in the frequency is significant, i.e., $\chi^{2}=16.114, \mathrm{df}=1, \mathrm{p}<.001$. As it can also be seen, there is a $66 \%$ preference for SR over $34 \%$ of OR among the learners. The results thus confirm the first hypothesis that there is a significant preference for self over other-repair among Iranian intermediate EFL learners.

TABLE 1

DESCRIPTIVE STATISTICS AND BINOMIAL TEST OF REPAIRS MADE BY INTERMEDIATE STUDENTS

\begin{tabular}{|l|l|l|l|l|l|l|}
\hline Category & N & Expected N & Residual & Observed Prop. & Test Prop. & Exact Sig. (2-tailed) \\
\hline SR & 99 & 74.5 & 24.5 & .66 & .50 & .000 \\
\hline OR & 50 & 74.5 & -24.5 & .34 & .50 & \\
\hline Total & 149 & & & 1.00 & & \\
\hline
\end{tabular}

Table 2 presents the descriptive statistics and Chi-Square test of the four types of repair resulting from the combination of repair-initiation and repair-completion (RI-RC), i.e., self-initiation self repair (SISR), self-initiation other-repair (SIOR), other-initiation self-repair (OISR) and other-initiation other-repair (OIOR). As can be seen, between the two types of repair completion for self-repair, the SISR is more frequent, i.e., 88, than the SIOR, i.e., 10. However, for other completion, OIOR is more frequent, i.e., 40, OISR, i.e., 11. The Chi-Square Test showed that the differences in the four types are significant, i.e., $\chi^{2}=107.779, \mathrm{df}=3, \mathrm{p}<.001$. These results provide more evidence to confirm the first hypothesis.

TABLE 2

DESCRIPTIVE STATISTICS AND CHI-SQUARE TEST OF THE FOUR OF REPAIRS MADE BY INTERMEDIATE LEARNERS

\begin{tabular}{|l|l|l|l|l|l|l|}
\hline & Observed N & Expected N & Residual & Observed Prop. & Test Prop. & Exact Sig. (2-tailed) \\
\hline SISR & 88 & 37.3 & 50.8 & .59 & .25 & .000 \\
\hline SIOR & 10 & 37.3 & -27.3 & .07 & & \\
\hline OISR & 11 & 37.3 & -26.3 & .07 & & \\
\hline OIOR & 40 & 37.3 & 2.8 & .27 & & \\
\hline Total & 149 & & & & & \\
\hline
\end{tabular}

Table 3 presents the descriptive statistics and binomial test of SRs and ORs made by advanced EFL learners. As can be seen, the frequency of SRs, i.e., 143, is much higher than ORs, i.e., 21. The Chi-Square Test showed that the difference in the frequency is significant, i.e., $\chi^{2}=90.756, \mathrm{df}=1, \mathrm{p}<.001$. As it can also be seen, there is a $87 \%$ preference for SR over $13 \%$ of OR among the learners. The results thus confirm the second hypothesis that there is $a$ significant preference for self over other-repair among Iranian advanced EFL learners.

TABLE 3

DESCRIPTIVE STATISTICS AND BINOMIAL TEST OF REPAIRS MADE BY ADVANCED LEARNERS

\begin{tabular}{|l|l|l|l|l|l|l|}
\hline Category & N & Expected N & Residual & Observed Prop. & Test Prop. & Exact Sig. (2-tailed) \\
\hline SR & 143 & 82.0 & 61.0 & .87 & .50 & .000 \\
\hline OR & 21 & 82.0 & -61.0 & .13 & & \\
\hline Total & 164 & & & 1.00 & & \\
\hline
\end{tabular}

Table 4 presents the descriptive statistics and Chi-Square test of the four types of repair, i.e., SISR, SIOR, OISR, and OIOR, made by advanced learners. As can be seen, the SISR and OIOR claim for the first and second highest frequencies among the combinations, i.e., 125 (78\%) and 19 (12\%), respectively. The Chi-Square Test showed that the differences in the occurrence of the four types are significant, i.e., $\chi^{2}=250.0, \mathrm{df}=3, \mathrm{p}<.001$, and thus provided further support for the psychological reality of establishing the four types of repair in conversational analyses. 
TABLE 4

DESCRIPTIVE STATISTICS AND CHI-SQUARE TEST OF THE FOUR OF REPAIRS MADE BY ADVANCED LEARNERS

\begin{tabular}{|l|l|l|l|l|l|l|}
\hline & Observed N & Expected N & Residual & Observed Prop. & Test Prop. & Exact Sig. (2-tailed) \\
\hline SISR & 128 & 41.0 & 87.0 & .78 & .25 & .000 \\
\hline SIOR & 15 & 41.0 & -26.0 & .09 & & \\
\hline OISR & 2 & 41.0 & -39.0 & .01 & & \\
\hline OIOR & 19 & 41.0 & -22.0 & .12 & & \\
\hline Total & 164 & & & & & \\
\hline
\end{tabular}

Table 5 presents the descriptive statistics and Chi-Square Test of SRs and ORs made by intermediate and advanced EFL learners. As can be seen, the number of SRs made by the advanced learners is more than the intermediate. The number of ORs made by the intermediate learners is, however, more than that of the advance. The Chi-Square Test showed that the differences in the occurrence of the SRs and Ors are significant and thus disconfirmed the third hypothesis that intermediate and advanced EFL learners will not differ significantly from each other in their preference for self over other-repair.

TABLE 5

DESCRIPTIVE STATISTICS AND CHI-SQUARE TEST OF THE REPAIRS MADE BY INTERMEDIATE AND ADVANCED LEARNERS

\begin{tabular}{|l|l|l|l|l|}
\hline \multirow{2}{*}{ Category } & \multicolumn{2}{|l|}{ Group } & \multirow{2}{*}{ Total } & Chi-Square Test \\
\cline { 2 - 5 } & Advanced & Intermediate & & \\
\hline SR & 143 & 99 & 242 & $\chi^{2}=19.170$ \\
OR & 21 & 50 & 71 & $\mathrm{df}=1$ \\
$\mathrm{p}<.001$
\end{tabular}

Table 6 presents the descriptive statistics and Chi-Square test of the four types of repair, i.e., SISR, SIOR, OISR, and OIOR, made by advanced learners. As can be seen, both groups show the same order in the two types of repair in that the first and second highest numbers of repairs have occurred in SISR and OIOR. However, while almost the same percentage of repair occurred in SIOR and OISR positions for intermediate learners, the number of advanced learners who allowed SIOR to occur, i.e., 15 (9\%), was more than OISR, i.e., 2 (1\%). The Chi-square test showed that the difference in the combination of repair initiation and completion was significant, i.e., $\chi^{2}=21.443$, df $=3$, $p<.001$ and thus provided further support to disconfirm the third hypothesis.

TABLE 6

THE DESCRIPTIVE STATISTICS AND CHI-SQUARE TEST OF THE FOUR TYPES OF REPAIR MADE BY ADVANCED AND INTERMEDIATE LEARNERS

\begin{tabular}{|c|c|c|c|c|}
\hline \multirow{2}{*}{\multicolumn{2}{|c|}{ Types of repair }} & \multicolumn{2}{|l|}{ Group } & \multirow{3}{*}{\begin{tabular}{|l} 
Total \\
216
\end{tabular}} \\
\hline & & \multirow{2}{*}{\begin{tabular}{|l|} 
Advanced \\
$128_{\mathrm{a}}$
\end{tabular}} & \multirow{2}{*}{\begin{tabular}{|l|} 
Intermediate \\
$\mathbf{8 8}_{\mathrm{b}}$
\end{tabular}} & \\
\hline \multirow{3}{*}{ SISR } & Count & & & \\
\hline & $\%$ within Same Turn & $59.3 \%$ & $40.7 \%$ & $100.0 \%$ \\
\hline & $\%$ within Group & $78.0 \%$ & $59.1 \%$ & $69.0 \%$ \\
\hline \multirow{3}{*}{ SIOR } & Count & $15_{\mathrm{a}}$ & $10_{\mathrm{a}}$ & 25 \\
\hline & $\%$ within Same Turn & $60.0 \%$ & $40.0 \%$ & $100.0 \%$ \\
\hline & $\%$ within Group & $9.1 \%$ & $6.7 \%$ & $8.0 \%$ \\
\hline \multirow{3}{*}{ OISR } & Count & $2 \mathrm{a}$ & $11_{b}$ & 13 \\
\hline & $\%$ within Same Turn & $15.4 \%$ & $84.6 \%$ & $100.0 \%$ \\
\hline & $\%$ within Group & $1.2 \%$ & $7.4 \%$ & $4.2 \%$ \\
\hline \multirow{3}{*}{ OIOR } & Count & $199_{\mathrm{a}}$ & $40_{\mathrm{b}}$ & 59 \\
\hline & $\%$ within Same Turn & $32.2 \%$ & $67.8 \%$ & $100.0 \%$ \\
\hline & $\%$ within Group & $11.6 \%$ & $26.8 \%$ & $18.8 \%$ \\
\hline \multirow{3}{*}{ Total } & Count & 164 & 149 & 313 \\
\hline & $\%$ within Same Turn & $52.4 \%$ & $47.6 \%$ & $100.0 \%$ \\
\hline & $\%$ within Group & $100.0 \%$ & $100.0 \%$ & $100.0 \%$ \\
\hline
\end{tabular}

Each subscript letter denotes a subset of Group categories whose column proportions do not differ significantly from each other at the .05 level.

\section{DisCUSSIONS}

The results of the present study provide not only enough evidence to support speakers preference of SR over OR, but also shed light on their nature in terms of foreign language learners' proficiency level. Although both intermediate and advanced learners prefer SRs, the number of SISRs made by intermediate learners is significantly fewer than those made by the advanced learners because they are basically syntactic in nature. After codifying the words/phrases comprising certain units of three textbooks, i.e., schemata, into three domains, i.e., semantic, syntactic and parasyntactic, Khodadady, Pishghadam and Fakhar (2010) found that syntactic schemata make up only $9.4 \%$ of all the units analyzed and taught as instructional material. As shown in Example 1, its intermediate producer had difficulty deciding which possessive determiner must be employed and, therefore, used the syntactic schema his first. However, she cut herself off in the middle of schema his and replaced it with her to agree with the agent of the Example, i.e., she. 
Example 1 (SISR): Intermediate

Learner: She cleaned hi- her room.

Khodadady (1997) and Khodadady and Herriman (2000) were the first scholars who treated repairs such as his and her as syntactic schemata, traditionally known as words. For these researchers schemata represent their utterers' ongoing personal experiences with words as they are employed in speech/writing under real conditions in real places at real time and for real purposes. Since the producer of Example 1, for example, employs a single possessive determiner for both female and male agents in her mother language, i.e., OU in Persian, she finds herself in a challenging situation when she refers to an agent calling for the obligatory selection of her instead of his in English. Because she has not had enough experiences with the two syntactic schemata to express herself, she employs his for both genders first and then repairs herself to reveal her developing proficiency level.

The proficiency-dependent nature of repairs is not limited to SRs. It is also reflected in ORs as shown in Example 2. The learner uses forget instead of forgot and her teacher corrects her by saying, "You mean you forgot." Although the schema forget is semantic in nature, the learner finds it difficult to add the element of time and thus reveals her developing syntactic knowledge of tense in English. In contrast to words, schemata not only contain semantic load but also depend syntactically on other schemata when they enter into discoursal relationships with each other. Although the learner does know what the schema forget represents she still needs to improve her proficiency by modifying its morph in order to agree with the discoursal schemata was and yesterday.

Example 2 (OIOR): Intermediate

Learner: I was busy yesterday and forget to write it

Teacher: You mean forgot. It's past

Learner: Yeah

However, as learners gain enough experience with the foreign language, the nature of repairs they make changes. Example 3 below was, for example, uttered by an advanced learner in the same position as Example 1, i.e., SISR. He had raised a question before and when he realized that the conversation between his classmates and teacher had shifted to a different topic, he produced the example as an indirect question requiring a certain repair on the part of teacher. The requested repair is not of a syntactic nature because it calls for a noun schema such as context. While syntactic schemata such as his and her are few in type but many in frequency, the semantic noun schemata such as context and place are many in type but few in frequency.

Example 3 (SISR): Advanced

Learner: My question was out of- I (.) just wanted to know

Although the producer of Example 3 did not repair himself directly and thus announced his indirect agreement with a change in topic, Example 4 shows how advanced learners paraphrase themselves to convey their messages. It provides a clear evidence for the argument that repairs are sometime made when no errors are committed (Jefferson, 1987). Some repairs are in fact made in order to reach a mutual agreement as regards what a speaker says and what the listener understands. In other words, conversation repairs are made to ensure that the schemata produced by addressers in their speech match the schemata their addressees retrieve from their personally developed repertoire. The closer the experiences of the addresser and addressee with the schemata negotiated, the more mutual the negotiation of meaning and the better they will understand each other.

Example 4 (SIOR): Advanced

Learner: You know all kind of - - this feeling is not bad there is uhm: the:: kind you want something fo::r you and others too

Teacher: Envy

Learner: Yeah thanks

\section{CONCLUSION}

The present study explored the type of repairs made by intermediate and advanced learners of English as a foreign language and showed that they prefer self-repair over other repair in their conversations. However, when both groups were compared with each other it was found that in spite of preferring self over other repair, advanced learners allow for significantly higher percentage of self-initiated other repair than their intermediate counterparts, indicating that the more proficiency the learners gain in their foreign language the more self-confident they become in seeking their addressees' contribution to the conversation. Since the addressees in this study were, however, teachers and hence occupied an authoritative position, further research is required to find out whether similar patterns will occur with peer addressees.

\section{REFERENCES}

[1] Bilmes, J. (1992). Dividing the rice: A microanalysis of the mediator's role in a Northern Thai negotiation. Language in Society, $21,569602$.

[2] Bilmes, J. (1993). Ethnomethodology, culture, and implicature: Toward an empirical pragmatics. Pragmatics, $3,387409$.

[3] Burke, P. (1993). The Art of Conversation. Cambridge: Polity Press. 
[4] Cicourel, A. (1992). The interpenetration of communicative contexts: Examples from medical contexts. In A. Duranti \& C. Goodwin (Eds.), Rethinking context: Language as an interactive phenomenon (pp. 291310). Cambridge: Cambridge University Press.

[5] Drew, P. \& Heritage. J. (1992). Talk at work: interaction in institutional setting. Studies in interaction sociolinguistics 3. Cambridge: Cambridge University Press.

[6] Ellis, R. \& Barkhuizen, G. (2005). Analysing Learner Language. Oxford: Oxford University Press.

[7] Garfinkel, H. (1967). Studies in Ethnomethodology. Cambridge: Polity Press.

[8] Goffman, E. (1959). The Presentation of Self in Everyday Life. New York: Doubleday.

[9] Goodwin, C. \& Heritage, J. (1990). Conversation Analysis. Annual reviews. Anthropol. 19, 283-307.

[10] Jefferson, G. (1987). On exposed and embedded correction in conversation, in G. Button and J. R. E. Lee (eds), Talk and Social Organization. Clevedon, Avon: Multilingual Matters (pp. 86-100).

[11] Khodadady, E. (1997). Schemata theory and multiple choice item tests measuring reading comprehension. Unpublished PhD thesis, the University of Western Australia.

[12] Khodadady, E. Pishghadam, R., \& Fakhar, M. (2010). The relationship among reading comprehension ability, grammar and vocabulary knowledge: An experimental and schema-based approach. Iranian EFL Journal, 6(2), 7-49.

[13] Khodadady, E., \& Herriman, M. (2000). Schemata theory and selected response item tests: from theory to practice. In A. J. Kunnan (Ed.), Fairness and validation on language assessment (pp. 201-222). Cambridge: CUP.

[14] Lerner, G. H. (2004). Conversation Analysis: studies from the first generation. John Benjamins Publishing Company: Amsterdam/Philadelphia.

[15] Liddicoat, A.J. (2007). An introduction to conversation analysis. New York, NY 10038: Continum.

[16] Markee, N. (2000). Conversation Analysis, Second Language Acquisition. Lawrence Erlbaum Associates, Inc.

[17] MathSoft (1999). S-PLUS 2000 Guides to Statistics, volume I. Data Analysis Product Division MathSoft Inc. Seattle, Washington.

[18] Mckay, S.L. \& Hornberger, N.H. (1996). Sociolinguistics and Language Teaching. New York: Cambridge University Press.

[19] Mehan, H. (1993). Beneath the skin and between the ears: A case study in the politics of representation. In S. Chaiklin \& J. Lave (Ed.), Understanding practice (pp. 241268). Cambridge: Cambridge University Press.

[20] Moerman, M. (1988). Talking culture: Ethnography and conversation analysis. Philadelphia: University of Pennsylvania Press.

[21] Schegloff, E. A. (1987). Between macro and micro: Contexts and other connections. In J. Alexander, B. Giesen, R. Munch, \& N. Smelser (Eds.), The micro-macro link (pp. 207234). Berkeley: University of California Press.

[22] Schegloff, E. A. (1990). On the organization of sequences as a source of "coherence" in talk-in-interaction. In B. Dorval (Ed.), Conversational organization and its development (pp. 5177). Norwood, NJ: Ablex.

[23] Schegloff, E. A. (1991). Conversation analysis and socially shared cognition. In L. R. Resnick, J. M. Levine, \& S. D. Teasley (Eds.), Socially shared cognition (pp. 150171). Washington, DC: American Psychological Association.

[24] Schegloff, E. A. (1992a). On talk and its institutional occasions. In P. Drew \& J. Heritage (Eds.), Talk at work (pp. xxx). Cambridge: Cambridge University Press.

[25] Schegloff, E. A. (1992b). Repair after next turn: The last structurally provided defense of intersubjectivity in conversation. American Journal of Sociology, 97, (5), 1295-1345.

[26] Schegloff, E. A., Jefferson, G., \& Sacks, H. (1977). The preference for self-correction in the organization of repair in conversation. Language, 53, 361382

[27] Schiffrin, D. (1991). Conversation analysis. Annual Review of Applied Linguistics, 11, 316.

[28] Stubbs, M. (1983). Discourse Analysis. Oxford: Basil Blackwell.

[29] Ten Have, P. (2004). Understanding qualitative research and ethnomethodology. London, Thousand Oaks, New Delhi: SAGE Publications.

[30] Wilson, T. P. (1991). Social structure and the sequenmtial organization of interaction. In D. Boden \& D. H. Zimmerman (Eds.), Talk and social structure (pp. 2243). Cambridge: Polity Press.

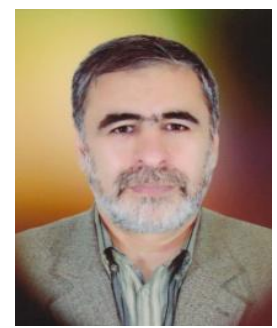

Ebrahim Khodadady was born in Iran in 1958. He obtained his $\mathrm{PhD}$ in Applied Linguistics from the University of Western Australia in 1998. He holds TESL Ontario and Canadian Language Benchmarks Placement Test (CLPBPT) certificates and has taught English as a first, second and foreign language to high school and university students in Australia, Canada and Iran.

$\mathrm{He}$ is currently an academic member of English Language and Literature Department at Ferdowsi University of Mashhad, Iran. He was invited as a VIP by Brock University in Canada in 2004 and served as the Associate Director of Assessment Center at George Brown College in Toronto for almost a year. His published books are Multiple-Choice Items in Testing: Practice and Theory (Tehran, Rahnama, 1999), Reading Media Texts: Iran-America Relations (Sanandaj, Kurdistan University, 1999) and English Language Proficiency Course: First Steps (Sanandaj, Kurdistan University, 2001). His main research interests are Testing, Language Learning and Teaching.

Dr. Khodadady is currently a member of TESL Ontario and European Society for Translation Studies. He is on the editorial board of Ferdowsi Review: An Iranian Journal of TESL, Literature and Translation Studies and has reviewed some research papers for Iranian Journal of Applied Linguistics and TESL Canada Journal as a guest reviewer. 


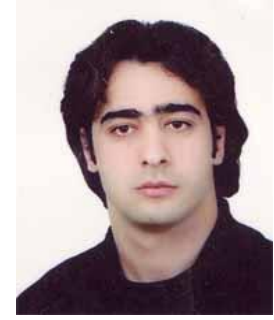

Jassem Alifathabadi was born in Iran in 1984. He obtained his MA in Applied Linguistics (English Language Teaching) from Ferdowsi University of Mashhad, Iran in 2011. He is a graduate of teacher training center and has been teaching English as a foreign language to guidance school and high school students for 8 years. His main research interests are Sociolinguistics, Language Learning and Teaching and Testing. 